Check for updates

Cite this: RSC Adv., 2019, 9, 24420

\title{
Cause analysis of chatoyancy of sapphires from Shandong, China $\uparrow$
}

\begin{abstract}
Jiaqi Yu, (D) Xuemei He* and Zhiyun Lu
Chatoyancy, that is, the cat's eye effect, has attracted many scholars' attention as a special optical effect. However, there are very few studies on the cat's eye effect of sapphire. The gemological features and formation mechanism of the chatoyancy of sapphires obtained from Shandong, China, were investigated by gemological microscopy, polarizing microscopy, scanning electron microscopy, infrared spectroscopy, X-ray fluorescence spectroscopy, UV-Vis spectroscopy, and Raman spectroscopy. Parallel orientations of the fracture surfaces were observed; light reflected on them, and an bright light band was formed perpendicular to them. No solid inclusions were detected under polarized light, and no absorption peaks of the solid inclusions were measured by Raman spectroscopy. In contrast, needle inclusions resulted in chatoyancy in other gemstones; parallel fracture surfaces with fluid inclusions above cause chatoyancy in sapphires. In this study, the origin of the cat's eye effect of sapphire was analyzed innovatively, and its phenomena were characterized concretely. In addition, this study provides a novel strategy to explain the mechanism of chatoyancy in the field of gemology and will be helpful for sapphire classification and quality evaluation.
\end{abstract}

Received 13th May 2019

Accepted 22nd July 2019

DOI: $10.1039 / c 9 r a 03585 k$

rsc.li/rsc-advances crystallize in the early alkaline basalt magma rich in $\mathrm{Al}$ and poor in $\mathrm{Si}$ at a great depth under high pressure. ${ }^{\mathbf{1 4}}$ One of the most prominent features of the sapphires obtained from Shandong is the coexistence of primary and secondary ores; this area mainly contains magmatic-type sapphires, which are mainly distributed in the central part of Shandong. ${ }^{15,16}$ Besides, Shandong sapphires are rich in solid inclusions and fluid inclusions. The solid inclusions include zircon, corundum, feldspar, spinel, and rutile; ${ }^{17}$ the fluid inclusions are mainly $\mathrm{CO}_{2}, \mathrm{H}_{2} \mathrm{~S}$ and $\mathrm{N}_{2}$, which can indicate the composition of the corundum magma system. ${ }^{18}$

In addition, the analyses of Shandong sapphires show Fe as the main chromophore, with minor $\mathrm{Ti}$, which is one of the important reasons for the deep color of the Shandong sapphire. ${ }^{15}$ Another important feature of the Shandong sapphire is the well-developed color zones, showing hexagonal, angular and flat color belts in the direction vertical to the $C$ axis. ${ }^{19}$ The direct formation of a color belt in sapphires is related to the fluctuation of $\mathrm{Fe}^{3+}$ concentration. ${ }^{20}$ Because the Shandong sapphire is darker in color, according to the Mössbauer spectrum data, the color can be improved by increasing the $\mathrm{Fe}^{3+} / \mathrm{Fe}^{2+}$ ratio with oxidation or reduction.

Shandong sapphires commonly show special optical effects such as asterism; ${ }^{21}$ however, they rarely show chatoyancy. Asterism of the Shandong sapphire is caused by directional acicular rutile inclusions, ${ }^{8}$ but to the best of our knowledge, the formation mechanism of chatoyancy in sapphires remains unclear. To clarify this issue, the mechanism of chatoyancy of the sapphires of Shandong has been
School of Gemology, China University of Geosciences, Beijing 100083, China. E-mail: hexuemei@cugb.edu.cn

$\dagger$ Electronic supplementary information (ESI) available. See DOI: 10.1039/c9ra03585k 
analyzed typically. Sapphires have long received attention as technologically sensitive materials because of their mechanical and optical properties; thus, sapphires are widely valued in the material industry. ${ }^{22-25}$ Considering the importance of sapphires, it is necessary to study them in all aspects, including their special optical effects. The aim of this study was to help determine the classification, systematic study, and quality evaluation of sapphires and provide research ideas for the cause analysis of cat's eye phenomena of other gemstones.

\section{Materials and methods}

Seven Shandong sapphire samples, showing slightly different chatoyancy, were collected (Fig. 1), and the descriptions of the samples are shown in Table 1 . The samples were polished to a cabochon cut and divided into two groups according to their color and chatoyancy effects: greenish-blue series A and yellowish-green series B.

All sapphire samples were investigated using gemological methods, spectroscopic analysis and chemical analysis. Conventional experiments were conducted in the Gem Testing Laboratory of the Gemological Institute, China University of Geosciences, Beijing. Ultraviolet-visible spectrophotometry was

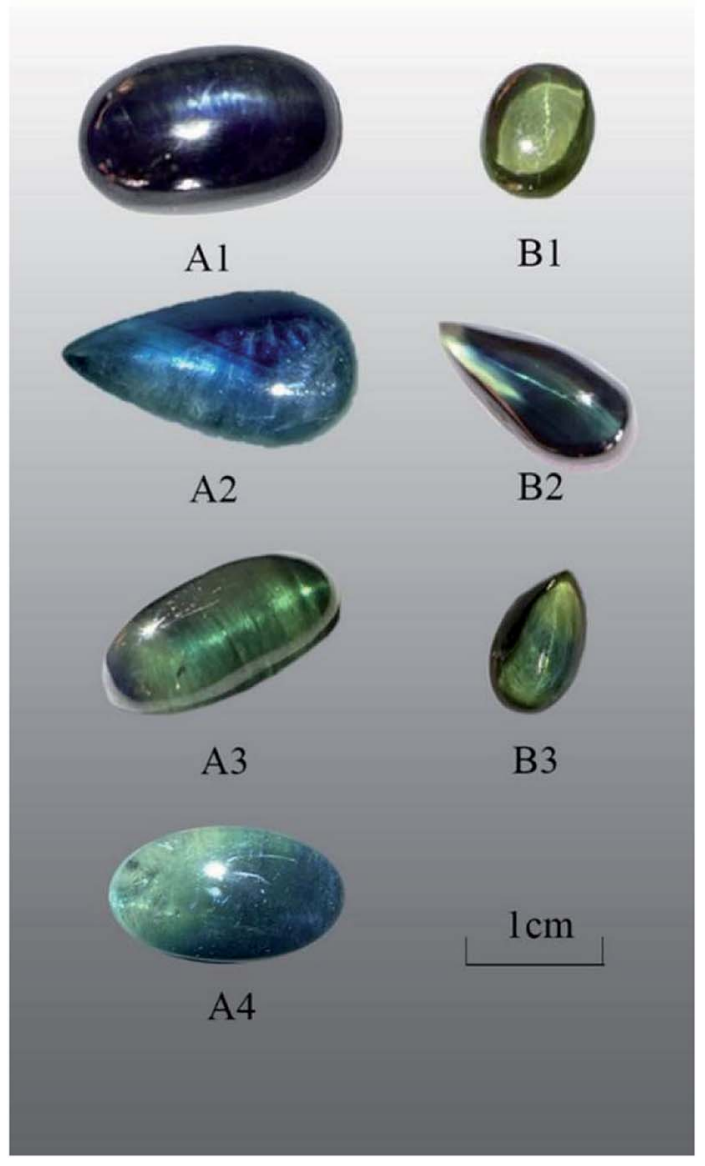

Fig. 1 Photograph of all samples. carried out with a Shimadzu UV-3600 UV-Vis spectrophotometer (200-900 nm, high speed, 0.5). An EDX-7000 Energy Dispersive X-ray fluorescence spectrometer was used $(50 \mathrm{kV}, 113 \mu \mathrm{A}, 30 \%$ DT). The microstructure was observed using gemological microscopy, polarizing microscopy, and SEM (Zeiss Ultra Plus, acceleration voltage from 10 to $15 \mathrm{kV}, 1 \mathrm{~atm}, 5-15 \mathrm{~mm}$ ). An HREvolution Laser Microscopic Raman Spectrometer of HORIBA (200-4000 $\mathrm{cm}^{-1}$, excitation wavelength of $532 \mathrm{~nm}$, laser energy of $100 \mathrm{~mW}$, resolution of $1 \mathrm{~cm}^{-1}$ ) was used to measure the samples' chemical composition. Samples were tested by infrared spectroscopy with a Tensor 27 Fourier Infrared Spectrometer $\left(4000-100 \mathrm{~cm}^{-1}, 210-230 \mathrm{~V}, 50-60 \mathrm{~Hz}\right.$, reflection method).

\section{Results}

\subsection{Gemological properties}

The samples in series A exhibited poor transparency and showed a large number of inclusions when observed with the naked eyes. The light band of A1 and A2 was bright and thick, whereas that of A3 and A4 was slightly thinner. The physical and chemical properties of sapphire in the Changle area are similar. ${ }^{19}$ The color distribution of series A was uneven with color zones. All samples exhibited refractive index of 1.76 and specific gravity of 3.99-4.03. Series A showed obvious medium dichroism with dark blue/greenish-blue color, whereas series B showed weaker dichroism with yellowish-green/brownish-green color.

All samples showed absorption spectra in the blue region with an absorption band (Fe + Ti spectrum) at around $450 \mathrm{~nm}$. The samples did not react with the Charles color filter and showed no fluorescence at either long or short-wavelength UV light.

\subsection{Microscopic observation}

Microscopy images show many fracture surfaces in almost all the samples of series A and B. The fractures have approximately parallel orientations (Fig. 2a) with a mass of fluid inclusions above (Fig. 2b), and the light band is perpendicular to them. Large amounts of multiphase inclusions lead to a misty, translucent, and uneven appearance (Fig. 2b).

The light band of sample A1 was oriented parallel to the straight color belt and from previous studies, it is clear that the color belt of a sapphire is compatible with its crystal structure. Series B showed large numbers of veil-like and fingerprint-like microfissures. Fluid inclusions tend to be clustered and distributed on the fracture surface; these are mostly colorless, transparent, and irregular in shape. Under a spotlight, series A showed a thick light band (Fig. 2c). Sample B2 showed a thin light band and under $40 \times$ magnification, dense twin striae perpendicular to the light band and arranged in a regular straight orientation were seen (Fig. 2d). The corundum with more developed cracks means obvious late melt infiltration metasomatism. ${ }^{26}$ In a previous report, a systematic study was performed to investigate the effect of crystallographic orientation on the 
Table 1 Description of different samples

\begin{tabular}{|c|c|c|c|c|c|}
\hline Sample & Color & Weight & Relative density & Morphology & Description of light band \\
\hline A1 & Blue-green & $7.90 \mathrm{ct}$ & 4.000 & Oval cambered & Thin, inflexible \\
\hline A2 & Greenish-blue & $6.80 \mathrm{ct}$ & 4.018 & Water drop profile & Thick, inflexible \\
\hline $\mathrm{A} 4$ & Blue-green & $4.74 \mathrm{ct}$ & 3.986 & Oval cambered & Thin, inflexible \\
\hline B1 & Yellowish-green & $1.48 \mathrm{ct}$ & 4.012 & Oval cambered & Thin, bright, and flexible \\
\hline B2 & Greenish-blue & $2.31 \mathrm{ct}$ & 4.029 & Water drop profile & Thin, bright, and flexible \\
\hline
\end{tabular}

deformation and cracking of sapphires by means of nanoindentation using spherical indenters. ${ }^{27}$ The study of the composition and properties of deep fluids has become one of the hotspots in recent years. Besides, the fluid components in inclusions or crystal gaps are the real records of the fluids in the earth.

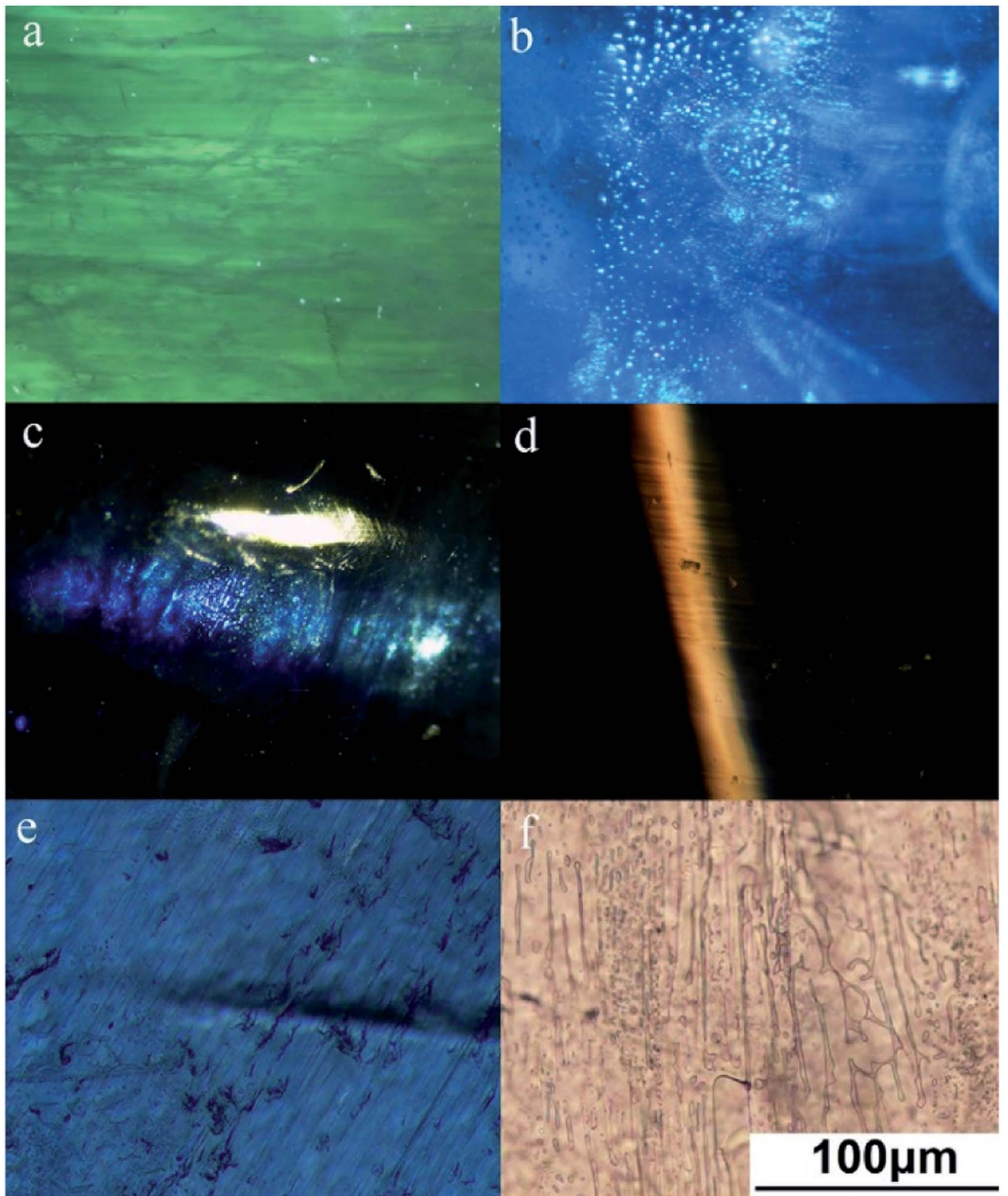

Fig. 2 Microscopy images of samples: (a) fractures of sample A3, (b) fluid inclusions of sample A2, (c) fracture surfaces of sample A2, (d) dense twin striae of sample B2, and (e and f) microfractures in polarizing microscopy with single polarization. 


\subsection{Polarizing microscopy}

Because some samples are gemstone grade and cannot be treated destructively, a representative sample A1 was selected to be cut into two $0.03 \mathrm{~mm}$ form chips along two directions: parallel and perpendicular to the light band. Sample A1 showed straight light band parallel to the angular color belt. The bottom plane of the sample was vertical to the $c$ axis, and the direction of the chips is the direction of $\overline{1} 2 \overline{1} 0$ and $10 \overline{1} 0$. Sample A1 showed directional microfractures under a polarizing microscope (Fig. 2e) and no obvious solid inclusions above the fractures.

When observed with a higher magnification, the microfractures showed abundant directional fluid inclusions that were irregular, elliptic, or beaded in shape (Fig. 2f). They were interconnected and formed a crisscross network. The elongated forms of the fluid inclusions indicate fluid flow along the fissure during crystal growth and the instability of the crystalline environment. ${ }^{28}$ This envelope is oriented along the closed intra-crystal fissure and is a false secondary cause. Such symmetrical cracks are believed to be caused by defects and dislocations during growth and not by dendrite growth.

\subsection{Scanning electron microscopy}

SEM was used to observe the micromorphology of the sample surface; a representative sample A1 was selected for SEM tests. The sample structure was tight with a smooth fracture surface and showed no obvious solid inclusions. Under a high magnification, flat growth texture and a fine growth pattern were seen locally (Fig. 3), and the overlapping crystal surface steps and top angles were consistent. We also found hexagonal growth lines on the smooth surface with an angle of about 120 degrees. These growth patterns reflected the crystal growth mechanism, which is a typical layer growth model. The theory of the layer growth of crystals has some limitations due to the influence of environment; thus, the actual growth of crystals does not fully follow the ideal theory of layer growth.

\subsection{XRF}

XRF detection was carried out on the samples, and the data of element composition and the spectra of each sample were obtained. The 10 elements with higher content in the samples were summarized and arranged in the form of oxides (Table 2).

Sapphire is an allochromatic mineral whose trace element concentration depends on the origin and has influence on the color. The results of XRF showed that the highest content of $\mathrm{Al}_{2} \mathrm{O}_{3}$ is about $97-99 \%$, which is the main component of the sample. Impurity elements exist in ionic lattices as isomorphic or mechanical mixtures, while $\mathrm{Fe}_{2} \mathrm{O}_{3}$ and $\mathrm{SiO}_{2}$ contents are higher, accounting for around $2 \%$ in total. The content of $\mathrm{Fe}$ oxides is slightly higher than that of $\mathrm{SiO}_{2}$, which is about 0.9$1.2 \%$. Because of the close coordination radius and the same valence state as that of $\mathrm{Al}^{3+}$, Fe mainly exists in the form of $\mathrm{Fe}^{3+}$. In addition, there are small amounts of transition metal ions such as Ti and Cr. Because of the relatively high content of Fe in the Shandong sapphire, the fluorescence of the sapphire will be inhibited, which is similar to previous gemological studies. The valence information of iron ions can be obtained from the difference in the total iron and titanium contents mentioned above. ${ }^{29}$ According to the principle of isomorphism, in order to replace $\mathrm{Al}^{3+}$ in sapphires, $\mathrm{Ti}^{4+}$ must replace two $\mathrm{Al}^{3+}$ ions at the same amount of $\mathrm{Fe}^{2+}$ to maintain charge balance. ${ }^{30,31}$ The proportion of $\mathrm{Ti}^{4+}$ and $\mathrm{Fe}^{2+}$ should be close to $1: 1$; thus, the most dominant element in total iron should be $\mathrm{Fe}^{3+}$.

\subsection{UV-Vis spectra}

The characteristics of the absorption spectra of different color varieties were investigated by ultraviolet-visible (UV-Vis) absorption spectroscopy. The absorption peaks of all samples were mainly concentrated in the following four regions: 200$400 \mathrm{~nm}, 430-470 \mathrm{~nm}, 520-600 \mathrm{~nm}$ and 710-800 nm (Fig. 4). ${ }^{32,33}$ Except for the clear absorption peaks in the second region, the other three regions showed wide absorption bands and a few absorption peaks. The intensities at 377 and $452 \mathrm{~nm}$ in the UVVis spectrum of A1 were stronger than that of A3 and A4.

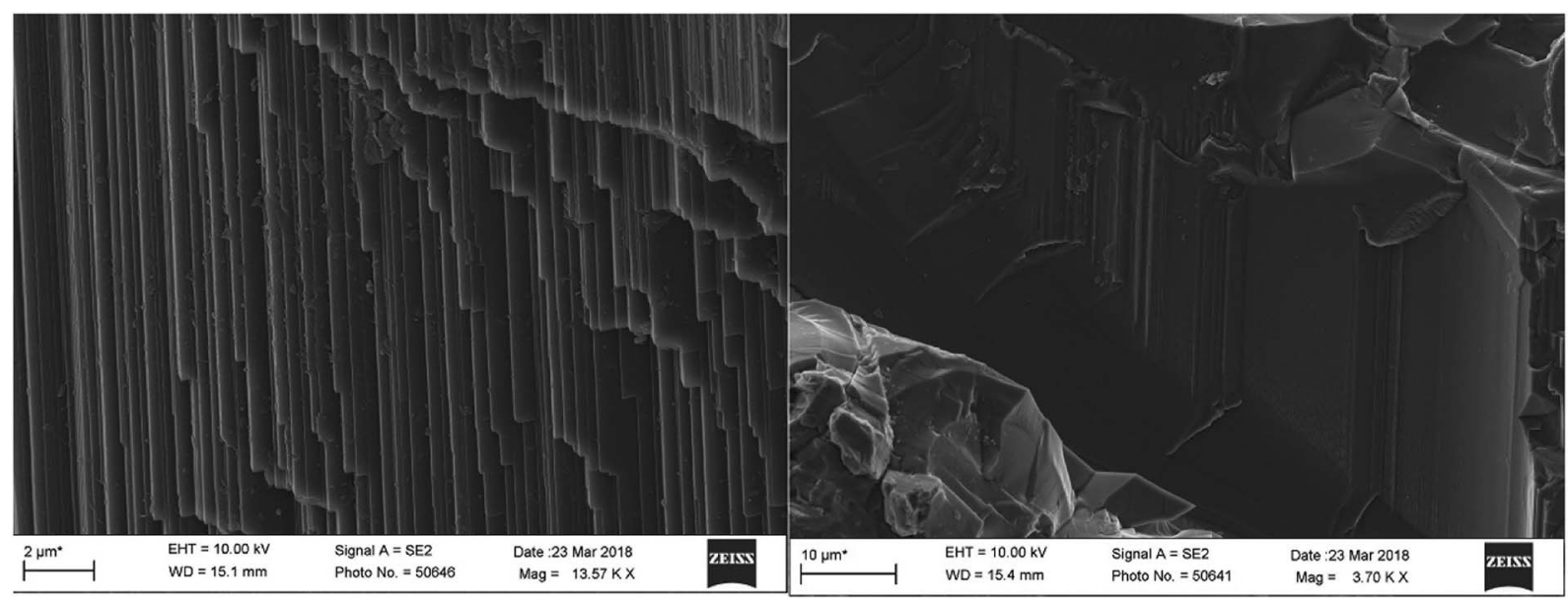

Fig. 3 Straight growth lines (left) and hexagonal growth texture (right) of sample A1. 
Table 2 X-ray fluorescence spectrum data of samples

\begin{tabular}{llllllllll}
\hline Content (\%) & $\mathrm{Al}_{2} \mathrm{O}_{3}$ & $\mathrm{Fe}_{2} \mathrm{O}_{3}$ & $\mathrm{SiO}_{2}$ & $\mathrm{SO}_{3}$ & $\mathrm{TiO}_{2}$ & $\mathrm{Ga}_{2} \mathrm{O}_{3}$ & $\mathrm{~K}_{2} \mathrm{O}$ & $\mathrm{CaO}$ & $\mathrm{CuO}^{2}$ \\
\hline $\mathrm{A} 2$ & 97.601 & 0.940 & 1.125 & 0.287 & 0.023 & 0.024 & - & - & - \\
$\mathrm{A} 3$ & 98.716 & 0.926 & - & 0.311 & 0.023 & - & 0.008 & 0.012 & 0.004 \\
$\mathrm{~B} 1$ & 97.484 & 1.219 & 0.920 & 0.323 & - & 0.026 & 0.016 & 0.010 & 0.002 \\
$\mathrm{~B} 2$ & 97.470 & 1.063 & 0.940 & 0.400 & 0.038 & 0.020 & 0.059 & 0.006 & - \\
$\mathrm{B} 3$ & 97.659 & 1.077 & 0.960 & 0.263 & - & 0.033 & - & 0.008 & - \\
& & & & & & & & &
\end{tabular}

Pure $\alpha-\mathrm{Al}_{2} \mathrm{O}_{3}$ should be colorless because of no selective absorption of light but precisely because of the complexity of geological conditions, corundum generally contains trace impurity elements such as $\mathrm{Fe}, \mathrm{Ti}, \mathrm{Cr}, \mathrm{Ni}$, and $\mathrm{Mn}$. These impurity elements can exist in the form of isomorphism in the crystal lattice of sapphire, and light waves can be selectively absorbed in the crystal structure, finally showing the corresponding color.

According to the XRF data, the main chromogenic element in sapphires is Fe, which can exist in the bivalent or trivalent state. The essence of Shandong sapphire color formation is the result of the interaction of absorption mechanisms such as $\mathrm{Fe}^{3+}, \mathrm{Fe}^{2+}-\mathrm{Ti}^{4+}, \mathrm{Ti}^{3+}, \mathrm{Fe}^{2+}-\mathrm{Fe}^{3+}$, and $\mathrm{Fe}^{2+}-\mathrm{O}^{2-} \cdot{ }^{34}$ The green tone in sapphires is the result of the superposition of yellow tone and blue tone. The former is generally considered to be due to the interaction of $\mathrm{Fe}^{3+}-\mathrm{Fe}^{3+}$ coupled ion pairs, while the latter is related to the electron transfer of $\mathrm{Fe}^{2+}-\mathrm{Ti}^{4+} \cdot{ }^{35}$ The absorption peaks at 375,387 and $450 \mathrm{~nm}$ can be attributed to the transition of ${ }^{6} \mathrm{~A}_{1}-{ }^{4} \mathrm{~A}_{1} 4 \mathrm{E}(\mathrm{G})$ of $\mathrm{Fe}^{3+}$ and the broadband absorption around $500-700 \mathrm{~nm}$ is caused by the charge transfer between $\mathrm{Fe}^{2+}$ and $\mathrm{Ti}^{4+} \cdot 36$

\subsection{Infrared spectra}

The infrared spectra of samples are shown in Fig. 6, and we can see that the absorption peaks are mostly concentrated in the range of $400-1000 \mathrm{~cm}^{-1}$. The frequencies of the absorption peaks tend towards the low frequency region, which are strongly absorbed in the low frequency band, while there is no characteristic absorption peak in the range of $1000-2000 \mathrm{~cm}^{-1}$, and the spectrum is smooth. The absorption peaks of the samples are observed around $472 \mathrm{~cm}^{-1}, 622 \mathrm{~cm}^{-1}, 665 \mathrm{~cm}^{-1}, 700 \mathrm{~cm}^{-1}$, $811 \mathrm{~cm}^{-1}$ and $870 \mathrm{~cm}^{-1}$ (Fig. 5), ${ }^{30,37}$ while the peak at $472 \mathrm{~cm}^{-1}$ is sharper. Actually, the stretching and bending vibrations of Al$O$ result in these special peaks.

Since the infrared spectra mainly reflect the vibrational information of a mineral skeleton structure, for the samples in this experiment, the chemical composition and crystal structures of gemstones were almost unchanged, which could explain why the infrared spectra of gemstones were very similar. According to previous analysis, transition metal ions such as Fe, $\mathrm{Ti}$ and $\mathrm{Cr}$ will replace few $\mathrm{Al}$ ions and occupy their positions, causing a change in vibration because of the difference in radius, atomic spacing and bonding force between these transition metal ions and $\mathrm{Al}$ ions, which is reflected in the shift in the characteristic absorption peaks in the spectra.

\subsection{Raman spectra}

All samples were tested by Raman spectroscopy, and samples of different colors had similar Raman spectra but slightly different locations. The color differences indicate differences in the concentrations of chromogenic ions in the samples. The Raman shift is a characteristic feature because of the difference in the bond energies and bond lengths of the impurity ions, such as $\mathrm{Fe}^{3+}, \mathrm{Fe}^{2+}$, and $\mathrm{Ti}^{4+}$, which replace $\mathrm{Al}^{3+}$ in the isomorphic mode. However, such ionic substitution did not cause significant changes in the main vibration modes of the samples, thus the distribution and strength of the wave crest of the Raman spectra remained regular.
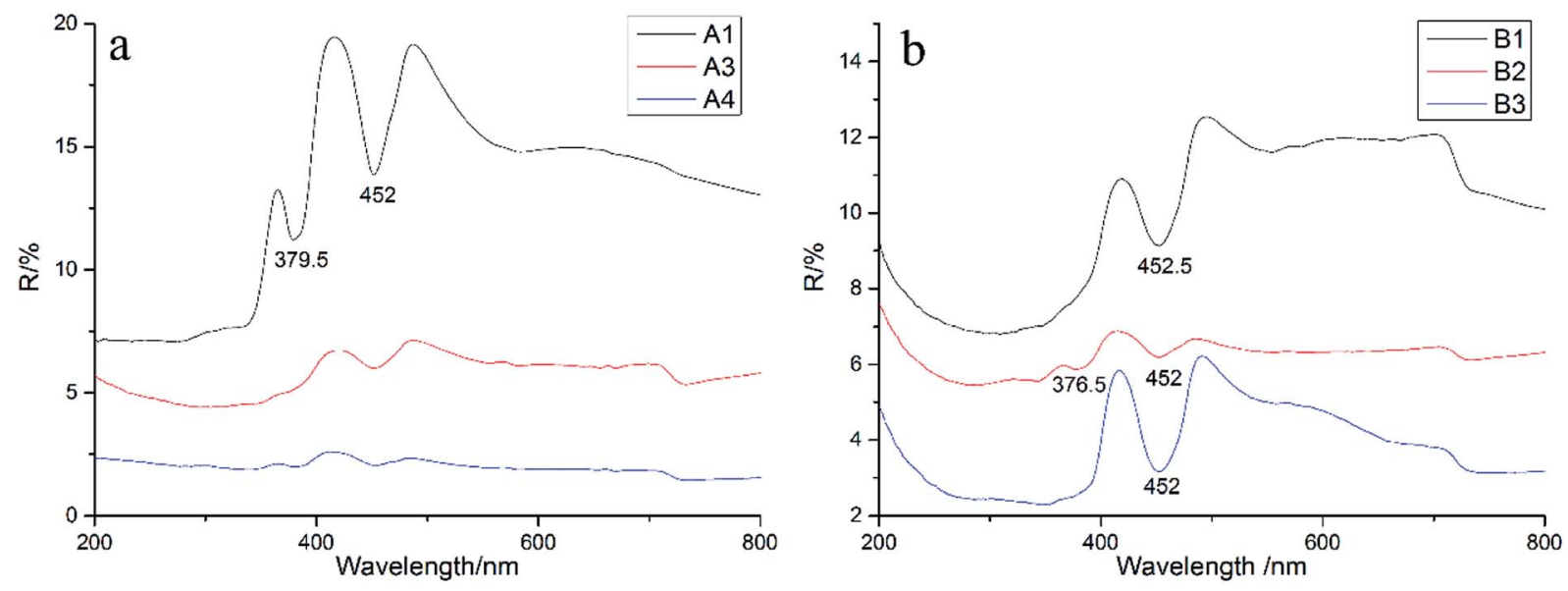

Fig. 4 Data of UV-Vis spectra of samples ((a) for series A, (b) for series B). 
a

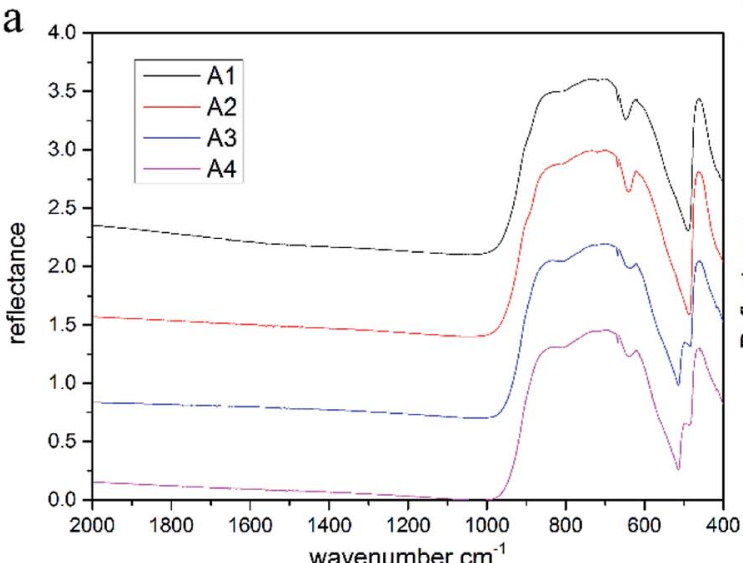

$\mathrm{b}_{20}$

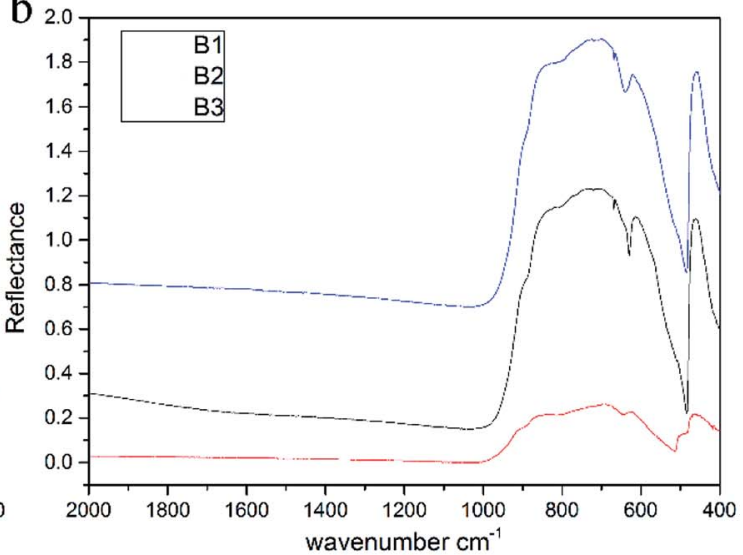

Fig. 5 Infrared spectra of different samples.

For example, samples A3 and B3 exhibit typical Raman displacement of a sapphire mainly concentrated at 300$800 \mathrm{~cm}^{-1} .^{38,39}$ The samples showed similar spectra with characteristic peaks caused by seven Raman-active vibrations of $\mathrm{Al}_{2} \mathrm{O}_{3}$ located at $748,645,575,450,416,432$, and $378 \mathrm{~cm}^{-1}$ (Fig. 6). ${ }^{28,32,33}$ The peak caused by the $\mathrm{A}_{1 \mathrm{~g}}$ vibration of $\mathrm{Al}^{3+}$ displacement at $416 \mathrm{~cm}^{-1}$ was the strongest and sharpest peak.

The intensity of a Raman peak is positively correlated with the ion concentration to some extent. The content of Fe was the highest except that of $\mathrm{Al}$ according to XRF, which was also reflected in the spectra. The peak at $245 \mathrm{~cm}^{-1}$ is caused by the $\mathrm{E}_{\mathrm{g}}$ vibration of $\mathrm{Fe}^{3+}$ displacement, while the Raman displacement of $\mathrm{Fe}^{2+}$ observed mainly at $426 \mathrm{~cm}^{-1}$ is not found in the spectrogram, which shows that Fe mainly exists in the form of $\mathrm{Fe}^{3+}$ in the sample.

In addition, characteristic absorption peaks of the solid inclusions were not detected in the microscopic Raman test. Thus, we concluded that the Shandong sapphire's chatoyancy was not caused by solid inclusions as thought previously.

\section{Discussion}

The effects of structure and composition on the genesis of the cat's eye effect of sapphire were comprehensively analyzed.

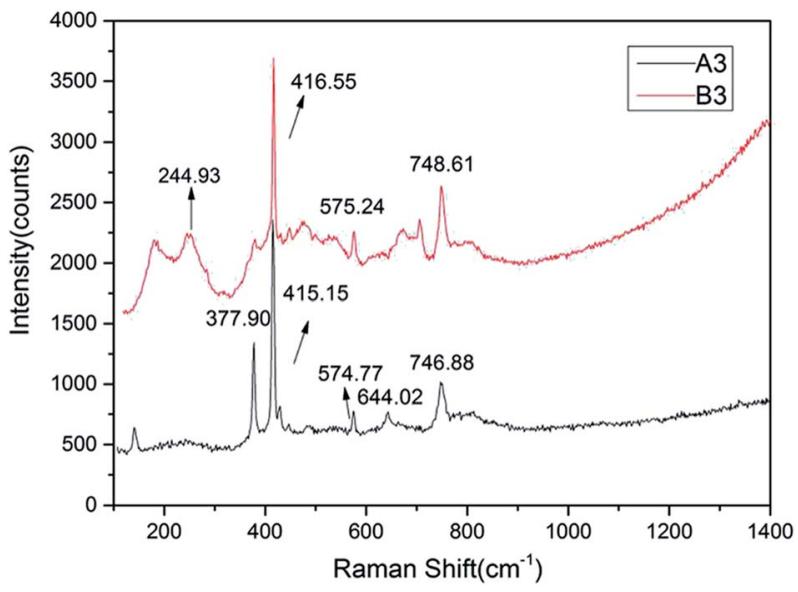

Fig. 6 Raman displacement of samples A3 and B3.
Unlike the chatoyancy effect of other gemstones, which is typically caused by parallel needle-like or tubular inclusions, one of the formation mechanisms of the cat's eyes effect in sapphire involves a large number of internal parallel fracture surfaces. Microscopic observations revealed abundant irregularly shaped multiphase inclusions gathered together, forming a complex fingerprint network, and chatoyancy appears because of the existence of such directional fluid inclusions. We can orientate the chatoyancy effect through some samples' color belt. The light band of the sample is parallel to the straight color belt, while the direction of the color belt is consistent with the hexagonal cylinder, that is, the direction of the healing crack is perpendicular to the color belt. Therefore, the distribution of the healing fissure tends to be vertical to the hexagonal cylinder of a crystal. The SEM results showed only finely laminated growth lines and no solid inclusions. In contrast, if the light band was caused by directional solid inclusions as assumed, SEM observations should show the existence of solid inclusions, but they were not observed. Raman spectroscopy also revealed no solid inclusions, verifying the observations from SEM.

The results of the XRF test showed that the main component of the sample was $\mathrm{Al}_{2} \mathrm{O}_{3}$ and its content was the highest: about 97-99\%. The contents of Fe and Si were higher than those of other impurity elements. On the basis of the XRF data, the ultraviolet spectra analyzed the coloration mechanism of the samples. It was found that there were clear single absorption peaks at 452 and $377 \mathrm{~nm}$ produced by the crystal field spectra of $\mathrm{Fe}^{3+}$ related to the d-electron transition. The wide absorption band at $710-800 \mathrm{~nm}$ was related to the charge transfer of $\mathrm{Fe}^{2+}-$ $\mathrm{Fe}^{3+}$, indicating that the origin of the samples is basalt. In summary, we can conclude that Fe is mainly present in the form of $\mathrm{Fe}^{3+}$ in the sapphires obtained from Shandong. Infrared spectroscopy shows the vibration information of the mineral skeleton structure of a sample. For the samples studied in this paper, the mineral structures were basically unchanged.

Chatoyancy results because of the light reflection on the parallel fracture surface. Different cutting orientations may result in differences in the thickness and direction of the light band. However, the light band is not sharp because the 
inclusions are not dense enough. Overall, the study results indicate that chatoyancy is caused by fluid inclusions as well as fracture surfaces.

\section{Conclusion}

A sapphire's chatoyancy is a special optical effect among corundum materials. Chatoyancy appears because of the abundant gas-liquid inclusions in fracture surfaces. The chemical and physical characteristics and inner structures of sapphire samples were analyzed using microscopic observations, polarizing microscopy, SEM, and Raman spectroscopy. The results showed that one of the causes of chatoyancy in the Shandong sapphire is the large number of internal parallel fracture surfaces and the existence of such directional fluid inclusions. When the cambered gemstone was illuminated by a point light, the light reflected off the surface of the parallel cracks intensively, thus forming a bright light band on the top of the convex gemstone.

\section{Conflicts of interest}

There are no conflicts to declare.

\section{Acknowledgements}

We thank the Laboratory of the Jewelry College, China University of Geosciences, Beijing, for their support.

\section{References}

$1 \mathrm{~J}$. Hyrsl, Newly discovered rare cat's-eye gemstones and star gemstones, J. Gems Gemmol., 2002, 4(2), 46-48.

2 K. Schmetzer, H. Bernhardt and H. Gilg, Characterization of Oriented Inclusions in Cat's-eye, Star and Other Chrysoberyls, J. Gemmol., 2016, 35(1), 28-54.

3 S. Phattalung, S. Limpijumnong, J. Thienprasert and J. Yu, Magnetic states and intervalence charge transfer of $\mathrm{Ti}$ and Fe defects in $\alpha-\mathrm{Al}_{2} \mathrm{O}_{3}$ : the origin of the blue in sapphire, Acta Mater., 2018, 143, 248-256.

4 L. Sutherland, P. Piilonen, K. Zaw, S. Meffre and J. Thompson, Sapphire within zircon-rich gem deposits, Bo Loei, Ratanakiri Province, Cambodia: trace elements, inclusions, U-Pb dating and genesis, Aust. J. Earth Sci., 2015, 62(6), 761-773.

5 K. Kochelek, N. McMillan, C. McManus and D. Daniel, Provenance determination of sapphires and rubies using laser-induced breakdown spectroscopy and multivariate analysis, Am. Mineral., 2015, 100(8-9), 1921-1931.

6 T. Chulapakorn, S. Intarasiri, D. Bootkul and S. Singkarat, Identification of deposit types of natural corundum by PIXE, Nucl. Instrum. Methods Phys. Res., Sect. B, 2014, (331), 108-112.

7 P. Khamloet, V. P. Arnond and C. Sutthirat, Mineral inclusions in sapphire from the basalt-related deposit in Bo Phloi, Kanchanaburi, Western Thailand: indication of their genesis, Russ. Geol. Geophys., 2014, 55(9), 1087-1102.
8 Z. Dong, L. Yang and W. Wang, Study on the Origin of the Sapphire Deposit in the Changle Area, Shandong, Acta Geosci. Sin., 1999, 20(2), 177-183.

9 Y. Chen, Z. Liao and Q. Xue, Research on the inclusions of Shandong sapphire, Shanghai Geol., 2007, 103, 63-66.

$10 \mathrm{M}$. Yu and P. Zhang, The Main Color-causing Factors of Sapphires in Shandong Province, Contrib. Geol. Miner. Resour. Res., 2006, 21(2), 115-119.

11 Y. Song, W. Hu, Z. Jin and Y. Chen, Fluid and melt inclusions and their fluid species in corundum megacrysts from the basalts in Changle, Shandong province, Eastern China, Geochimica, 2006, 35(4), 333-345.

12 M. Hutchison, P. Nixon and S. Harley, Corundum inclusions in diamonds_discriminatory criteria and a corundum compositional dataset, Lithos, 2004, 77, 273-286.

13 X. Mo, Magma and Magmatic Rocks: Probes and Evolution Records of Deep Earth, J. Nat., 2011, 33(5), 255-259.

14 L. Wang and P. Wang, Genetic types and distribution of corundum gem deposits in China, J. Gems Gemmol., 2001, 3(3), 8-12.

$15 \mathrm{X}$. Yu, X. Niu and L. Zhao, Characterization and Origin of Zonal Sapphire from Shandong Province, China, JOM, 2015, 67(2), 391-397.

16 C. Simonet, E. Fritsch and B. Lasnier, A classification of gem corundum deposits aimed towards gem exploration, Ore Geol. Rev., 2007, 34(1), 127-133.

17 J. Guo, S. O'Reilly and W. Griffin, Corundum from Basaltic Terrains: A Mineral Inclusion Approach to the Enigma, Contrib. Mineral. Petrol., 1996, 122, 368-386.

18 Y. Song, W. Hu and Z. Jin, Fluid and Melt Inclusions in Changle Corundum Megacrysts in Shandong Province and Their Fluid Composition Characteristics, Geochemistry, 2006, 35(4), 377-387.

19 X. Li, Z. Yang, S. Huang, Y. Chen, X. Zeng and W. Zhou, FTIR Spectra and LA-ICP-MS Research of Growth Zones in Sapphire Bands from Changle, Shandong Province, Spectrosc. Spectral Anal., 2018, (2), 407-412.

20 Z. Zhang, Y. He, K. Yue and W. li, Characteristics and comparison of sapphire color belt in Changle, Shandong and Penlai, Hainan, Miner. Depos., 2002, 21(S1), 938-940.

21 P. Wang and G. Li, A Study of Inclusions in Sapphire from Shandong Province, Mineral Resources and Geology, 1996, 10(4), 251-255.

22 J. Bristow, S. Parker, A. Catlow, C. Richard, S. Woodley and A. Walsh, Microscopic origin of the optical processes in blue sapphire, Chem. Commun., 2013, 49, 5259-5261.

23 J. Bristow, D. Tiana, S. Parker and A. Walsh, Defect chemistry of $\mathrm{Ti}$ and $\mathrm{Fe}$ impurities and aggregates in $\mathrm{Al}_{2} \mathrm{O}_{3}, J$. Mater. Chem. A, 2014, 2, 6198-6208.

24 S. Liang, X. Zheng, J. Zhu and R. Yu, Coherent Topotactic Interface between Corundum and Rutile Structures, J. Phys. Chem. C, 2019, 123(1), 534-540.

25 M. Grobosch, C. Schmidt, W. Naber, W. Van Der Wiel and M. Knupfer, A photoemission study of interfaces between organic semiconductors and $\mathrm{Co}$ as well as $\mathrm{Al}_{2} \mathrm{O}_{3} / \mathrm{Co}$ contacts, Synth. Met., 2010, 160(3), 238-243. 
26 S. Chen, X. Li, F. Kong, L. Zhao and H. Chen, Mineral Characteristics and Origin Discussion of Corundum/ Sapphire in Cenozoic Alkali Basalts of the Changle, Western Shandong, China, Adv. Geosci., 2016, 116-128.

27 V. Trabadelo, S. Pathak, F. Saeidi, M. Parlinska-Wojtan and K. Wasmer, Nanoindentation deformation and cracking in sapphire, Ceram. Int., 2019, 45(8), 9835-9845.

28 J. Liu, P. Ni, K. Shen and J. Ding, Liquid immiscibility recorded in melt inclusions within corundum from alkaline basalt, Changle area, Shandong province, Eastern China, Acta Petrol. Sin., 2007, 23(1), 125-130.

29 G. Zhou, Y. Dong, J. Xu, H. Li, J. Si, X. Qian and X. Li, 140 mm sapphire crystal growth by temperature gradient techniques and its color centers, Mater. Lett., 2006, 60(7), 901-904.

30 X. Han, S. Guo, Y. Kang, Y. Lee and X. Feng, Colorizing Role of Iron and Titanium in Dark Blue Sapphire from Changle, Shandong, J. Chin. Ceram. Soc., 2018, 10, 1483-1488.

31 S. V. Nizhankovskii, N. S. Sidel'nikova and V. V. Baranov, Optical absorption and color centers in large Ti: sapphire crystals grown by horizontally directed crystallization under reducing conditions, Phys. Solid State, 2015, 57(4), 781-786.

32 Y. Xie, Analysis on UV-VIS Spectrum and Colouration Mechanism of Sapphire, J. Gems Gemmol., 2004, 6(1), 9-12.
$33 \mathrm{X}$. Lee, Causes of color formation and spectral characteristics of sapphire from Changle, Shandong province, Journal of the Graduates Sun Yat-Sen University (Natural Sciences, Medicine), 2015, 36(4), 60-73.

34 A. R. Moon and M. R. Phillips, Defect Clustering and Color in Fe, Ti: $\alpha-\mathrm{Al}_{2} \mathrm{O}_{3}, J$. Am. Ceram. Soc., 1994, 77(2), 356-367.

35 J. Liu, B. Hu and D. Zhang, Absorption Spectra, ESR and Impurity Distribution of Sapphire in Shandong Province, $J$. Inorg. Mater., 1992, 7(3), 366-369.

36 J. Mogmued, N. Monarumit, K. Won- and S. Satitkune, Spectroscopic properties for identifying sapphire samples from Ban Bo Kaew, Phrae Province, Thailand, J. Phys.: Conf. Ser., 2017, 901(1), 012-075.

37 J. Ding, Z. Lee and S. Lee, Discussion on the Infrared Spectrometry of Sapphire from Shandong Province, Metrology \& Measurement Technique, 2011, 38(7), 54-55.

38 Z. Zhang, Y. He and H. Li, Study on the effect of alkali elements on the crystallization of sapphire in Shandong province, Journal of the Graduates Sun Yat-Sen University (Natural Sciences, Medicine), 2006, 6, 967-971.

39 Z. Palanza, D. D. Martino, A. Paleari and G. Spinolo, MicroRaman Spectroscopy Applied to the Study of Inclusions Within Sapphire, J. Raman Spectrosc., 2008, 39(8), 10071011. 